drank in consequence much fluid. The quantity of urine passed was excessive and subsequent measurements showed an average of about ten pints per 24 hours. An analysis of the urine gave the following results: specific gravity, 1040; albumin, nil; and sugar, 5 per cent. The case was a typical one of diabetes mellitus. There was no discoverable cause for the disease. Both parents were alive and in good health and the patient's brothers and sisters were strong and healthy. There was no history of injury, fever, chill, or other exciting cause. This case was the more interesting to me as at the same time $I$ had two other cases of diabetes mellitus in boys, each aged about 11 years.

Some little time later, about the middle of October, the boy was admitted as an in-patient at the Royal Surrey County Hospital, Guildford, and was treated there for some weeks but was discharged without improvement. On Feb. 2nd, 1904, an eruption appeared on the skin. It was papular in character and chiefly confined to the extensor surfaces of the upper extremities, to the flexor and extensor surfaces of the lower extremities, and to the buttocks. On the knees, elbows, and buttocks the papules were very numerous and often confluent. The papules were roundish and well defined in outline when discrete. They were hard to the touch, of bluish-red colour, and at the apex of most of them was a yellow head which appeared to contain pus. Puncture, however, revealed the fact that the yellow matter was solid. Isolated papules were present practically all over the skin and on the tongue and mucous membrane of the mouth. The eruption appeared rather suddenly and was first noticed on the knees and elbows. The eruption was not painful but itched very much. There was tenderness on pressure and sitting, except on a soft cushion, was attended with much discomfort. From time to time some of the papules disappeared and were succeeded by fresh crops.

I believe that a case in a patient so young has not hitherto been recorded. The disease is exceedingly rare. Up to the

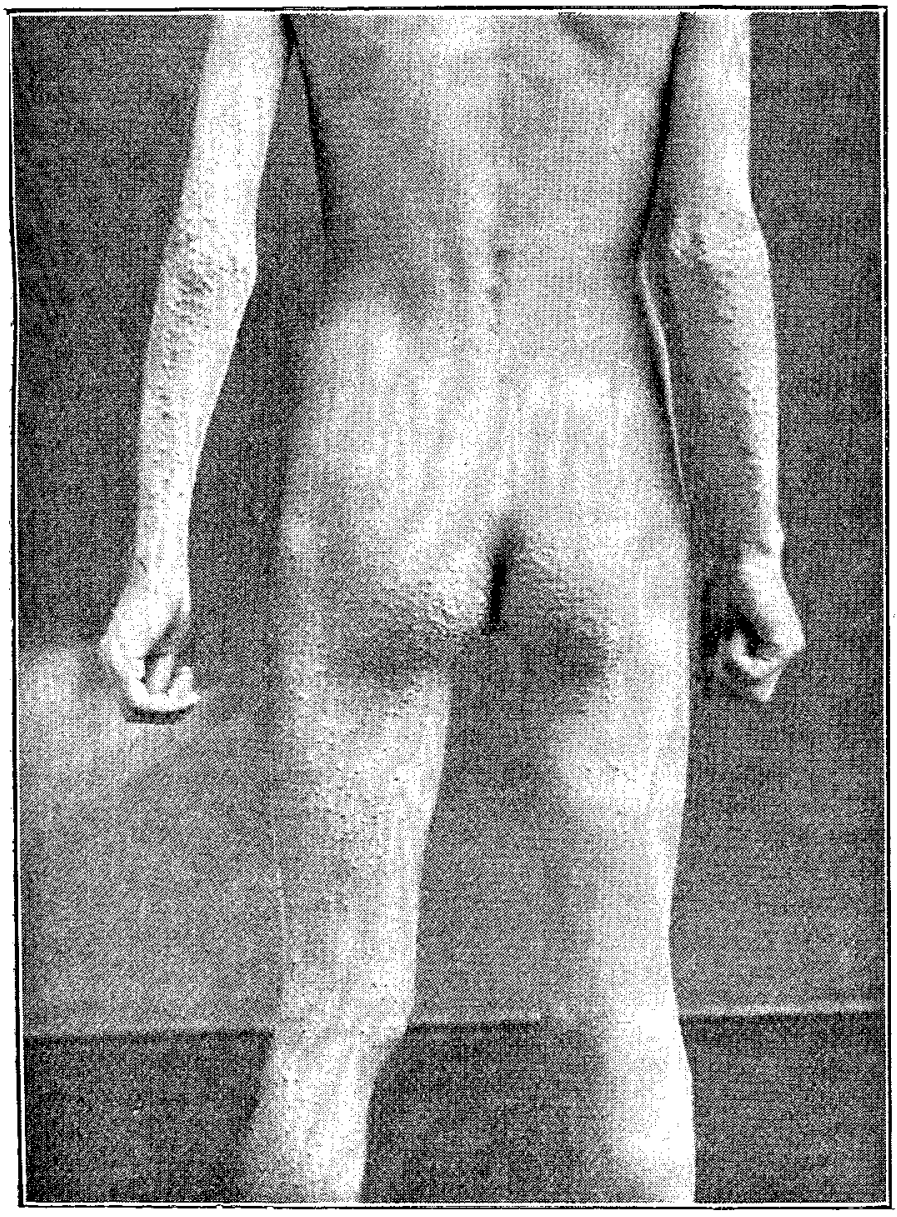

year 1900 only 30 cases were on record, the ages being between 21 and 57 years. ${ }^{1}$ In this case diabetes mellitus was typically present. In Crocker's case diabetes mellitus was present but was not suspected until the eruption drew attention to the real condition.

I Vide Crocker, Diseases of the Skin, vol. ii., p. 696.
Pathology _ " "The diseased process appears to be anatomically of the same nature as ordinary nodular xanthoma but with more inflammatory phenomena and less connective tissue growth" (Crocker).

Dr. Salaman has made sections of the skin and his description of the microscopical appearances is appended verbatim.

Full-length photographs of the patient were taken and show very fairly the distribution of the eruption.

Pathological Notes by Dr. SALAMAN. - Beneath the epidermis, and separated from it as a rule by a narrow layer of more or less normal corium, lie massive groups of cells ; the overlying epithelium is thinned out and in those places where the nodules are biggest the intervening corium has disappeared and the epithelium is only one or two cells thick. Deep in the corium are smaller nodules grouped around hair roots or sweat glands. In these positions the cells appear to be divided from pre-existing lymph spaces and channels. Growing out from the edges of the larger groups are straggling bands of cells in which occasionally appearances suggesting a lumen may be seen. Sections stained for fat show a great abundance of the latter, especially in the larger nodules; the fat exists in large globules; the cells containing it have the character of ordinary fat cells. In the outlying columns of cells and in the deeper nodules fat is more scanty and in smaller droplets. In the overlying epithelium fat is seen within the epithelial cells and in the neighbourhood of the larger nodules. The tumour cells, except where laden with fat, are mostly oval or cubical in shape and rather smaller than the cells of the Malpighian layer. They have a definite protoplasmic body and a slightly oval nucleus rather poor in chromatin. Stained with pyronin and methyl green no plasma cells are seen. Pigment granules are very scanty but are met with in the lower parts of the larger nodules.

Great Bookham.

\section{ABSCESS OF THE SPLEEN IN ENTERIC FEVER.}

NOTES OF TWO CASES, WITH ONE RECOVERY.

By AROHIBALD W. HARRINGTON, M.D. GLASG., LATE SENIOR RESIDENT ASSISTANT PHYSICIAN, GLABGOW FEVER HOSPITAL, RUCHILL.

THE rarity of abscess of the spleen in enteric fever may be judged from the fact that only four cases were noted in 577 necropsies at Hamburg and Leipsic. ${ }^{1}$ Murchison ${ }^{2}$ records two cases in which infarctions softened into a "puriform fluid" causing peritonitis and quotes five similar cases recorded by Robertson, Jenner, and Hoffmann. In an annotation in THE LANCET of July 8th, 1905, p. 95, a case recorded by Federmann in the Deutsche Medizinische Wochenschrift is summarised. This case was diagnosed after operation for purulent pleurisy when subphrenic suppuration was suspected from the bulging upwards of the diaphragm and the adhesion of the lower lobe of the left lung to it.

The difficulties of diagnosis are naturally very great and in a patient who is very ill a diagnosis may only be made on the onset of peritonitis and even then with difficulty. In my first case the abscess was discovered post mortem. The patient was extremely ill and semi-conscious. Some enlargement and tenderness of the spleen were noted and two rigors occurred. As there were numerous sloughs in the stools the rigors were ascribed to their separation. In the second case the diagnosis was based on the persistent pain, temperature, and sweating, pointing to suppuration in the left hypochondriac region. There were no rigors and no dulness over the base of the left lung. Splenic abscess seemed probable when the kidney was displaced far enough to enable one to make out that it was not enlarged or tender

The bacteriology of the cases shows that the ordinary pyogenic microbes were, as is so frequently the case in suppuration in enteric fever, the causal agents. In Case 1 , however, the bacillus typhosus was found in conjunction with the staphylococcus pyogenes aureus but the patient died from hæmorrhage in the acute stage of her illness

1 Curschmann: Nothnagel's Encyclopædia, Typhoid and Typhus Fevers, p. 183. 
when one would expect to find numerous typhoid bacilli in the spleen. The excellent recovery made by Case 2 is quite in accordance with published results, 15 out of 27 cases having recovered."3

CASE 1.- The patient, a married woman, aged 46 years, was admitted to Ruchill Hospital on Dec. 3rd, 1904 . It was impossible to fix the date of onset of her illness but she was said to have been ill for about two months and in bed for five weeks. Diarrhcea had been persistent and delirium had been present for a week. No further history couid be obtained. On admission the patient was very ill and delirious. Bedsores were present and both ears were discharging greenishyellow pus. There were very notable cardiac weakness, some bronchitis, and diarrhœa with " peasoup" stools containing curds and sloughs. No enlargement of the spleen could be detected. Widal reaction was positive in a dilution of 1 in 20 in 30 minutes. The urine was acid and contained a cloud of albumin; the diazo reaction was present. She had a severe rigor shortly after admission and another on the following day. Although the temperature kept high and the diarrhœa continued the patient improved slightly. Progressive enlargement of the spleen was noted and on Dec. 17th it was easily felt and appeared to be tender. On that date two moderate hæmorrhages from the bowel occurred followed on the 18th by two large hæmorrhages. The patient, who was delirious throughout, gradually sank and died on Dec. 20th.

On post-mortem examination very extensive and deep ulceration of the ileum and cæcum was found. One large ulcer extended down to the peritoneal coat, which was extremely thin. The spleen was considerably enlarged and showed numerous adhesions at its upper end. On incision an abscess cavity containing a large quantity of pinkish thick pus was opened up. This cavity hollowed out practically the entire organ. The other organs showed the changes incident to continued fever, the heart muscle being very soft and pale. A culture from the spleen proved the presence of abundant staphylococcus pyogenes aureus and bacillus typhosus.

CASE 2.-The patient, a man, aged 33 years, was admitted to Ruchill Hospital on June 6th, 1905. He had always been healthy but was addicted to alcohol. His attack of enteric fever was sharp and attended by severe diarrhoea. Widal reaction was positive, in a dilution of 1 in 50, in 45 minutes. No enlargement of the spleen was detected. The temperature fell to normal on the twenty-third day of illness but a relapse occurred on the thirty-first day. The temperature was again normal on the thirty-eighth day. From that day the patient made steady progress till July 23rd (fifty-eighth day), when he complained of severe pain in the left hypochondrium. On examination marked resistance was present but no swelling could be made out. The temperature rose that evening to $102 \cdot 2^{\circ} \mathrm{F}$. There was no shivering. By July 30 th the pain had considerably subsided. The temperature had remained elevated, being about $102^{\circ}$ in the evening and falling to about $100^{\circ}$ in the morning with some sweating. A swelling could be felt in the left hypochondrium just below the costal margin. On the 31 st the swelling projected well beyond the costal margin and by its shape could be definitely distinguished as kidney. It was not tender when pressed bimanually but pressure in an upward direction elicited considerable tenderness. Dulness on percussion was continuous from the swelling to the upper border of the ninth rib in the mid-axillary line. A probable diagnosis of abscess of the spleen was arrived at and Dr. Farquhar Macrae, who saw the patient in consultation, agreed.

On August 2nd Dr. Macrae removed a portion of the twelfth ib behind. The spleen was found enlarged and very adherent to the kidney. No softening of the organ could be made out by the finger. Sereral unsuccessful punctures were made with a large needle and, finally, pus was found at the lower end of the spleen where it was adherent to the kidney. The pus, which was in small amount (one ounce), was thick and greenish yellow. large tube was inserted and the wound was packed. The patient suffered a good deal of pain during the night following the operation. The temperature rose to $104^{\circ}$ owing to some pleurisy from accidental tearing of the pleura during the operation. On the following day, however, the temperature fell to normal and the patient made steady progress towards recovery. The wound healed slowly but was completely closed on Sept. 18th. Smear preparations of the pus showed the presence of very abundant cocci and on culture the organisms found were staphylococcus pyogenes aureus and streptococcus pyogenes.

Convalescence was interrupted by an osteomyelitis of the upper third of the right femur, which was operated upon on Sept. 20th. A large sequestrum was removed. Staphylococcus aureus and streptococci were found in cultures from the pus. The patient is now well.

I am indebted to Dr. A. Johnston, physician-superintendent, for permission to publish these cases.

Glasgow.

\section{EXTRAORDINARILY RAPID DIMINUTION OF RENAL DROPSY UNDER CITRATE OF CAFFEINE.}

By H. D. ROLLESTON, M.D. CANTAB., F.R.C.P. LoND, PHYSICIAN TO ST. GEORGE'S HOSPITAT;

AND

JOHN ATTLEE, M.D. CANTAB.,

CONSULTLNG PHYSICIAN TO THE MARGARET-STREET HOSPITAL FOR CONSUMPTION AND DISEASES OF THE CHEST, CAVENDISH-SQTARE, $W$.

THIS case appears worthy of being recorded because of the phenomenal and rapid loss of œdema and corresponding diminution of weight in a case of parenchymatous nephritis which got steadily worse under the usual methods of treatment. In brief, the patient lost his oedema and four and a half stones in weight in 16 days-i.e., an average loss of four pounds a day.

A man, 36 years of age, was first seen by one of us (J. A.) on March 8th last suffering with cedema of the legs below the knees. His urine contained over 10 parts per 1000 of albumin (Esbach). This quantity of albumin remained constant till June $23 \mathrm{rd}$, when it contained 8 parts per 1000 with a specific gravity of 1005 ; and on July 1st 2 parts per 1000 , with a specific gravity

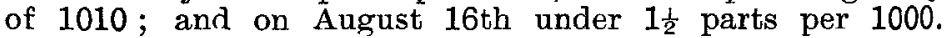
On March 20th Dr. G. L. Eastes reported: "Microscopy of centrifugalised deposit. The deposit is small in volume. It contains a moderate number of hyaline and granular casts, in a few of which are one or two tubal cells. There are also a very few renal cells free in the deposit. A trace of semen is present." The heart showed no hypertrophy or dilatation and no accentuation of the second sound over the aortic base. The pulse did not convey the impression of any increased tension and on two occasions the Riva-Rocci sphygmometer showed that the pressure was 132 and 130 millimetres of mercury respectively, which is within the limits of the normal for a healthy adult male. From March 8 th to May 10th, in spite of various methods of treatment, the cedema steadily increased and then remained stationary till June $5 \mathrm{th}$, the treatment being absolute rest in bed, hot air baths, restricted fluid, absence of chloride of sodium (these two latter from May 10th), and various drugsnamely, citrate of potassium, magnesium sulphate, digitalis, jalap, acetate of ammonium, Baillie's pill, decoction of scoparium, and citrophen (a combination of citric acid and paraphenetidin). From May 10 th to June 5 th the patient was intensely anasarcous, the odema extending up to the angles of the scapulæ, and the calves measured $15 \frac{3}{4}$ inches, as compared with $11 \frac{1}{4}$ inches when free from odema. The abdomen was enormously distended, the skin was tense, and there was much free fluid in the abdomen. There were signs of double hydrothorax. It was remarkable, however, that the face and eyelids were quite, and the hands and arms almost, free from any puffiness. It may be noted again in this connexion that there was no sign of any dilatation of the heart. The clinical chart showed that the urine passed on June 4th measured two pints. On the 5 th he was put on citrate of caffeine, seven and a half grains three times a day, which he continued to take till the 30 th, when the dose was gradually diminished until it was discontinued entirely about July 8th. During this time he was taking restricted fluids carefully measured out-namely, one and threequarter pints in 24 hours. The effect of the citrate of caffeine was manifest almost at once. The amount of the urine, which had previously been from two to two and a 